\title{
Intestinal Metaplasia
}

National Cancer Institute

\section{Source}

National Cancer Institute. Intestinal Metaplasia. NCI Thesaurus. Code C8360.

A morphologic finding indicating the replacement of epithelial tissue outside the intestines by intestinal-type epithelium. 